\title{
Irpinia earthquake 23 November 1980 - Lesson from Nature reviled by joint data analysis
}

\author{
Sergey A. Pulinets $\left({ }^{1}\right)$, Pierfrancesco Biagi $\left({ }^{2}\right)$, Valerio Tramutoli $\left({ }^{3}\right)$, \\ Anna D. Legen'ka $\left({ }^{4}\right)$ and Victor Kh. Depuev $\left({ }^{4}\right)$ \\ (1) Instituto de Geofísica, Universidad Nacional Autónoma de México, México \\ $\left(^{2}\right)$ Dipartimento Interateneo di Fisica «M. Merlin», Università degli Studi e Politecnico di Bari, Italy \\ $\left(^{3}\right)$ Dipartimento di Ingegneria e Fisica dell'Ambiente, Università degli Studi della Basilicata, Italy \\ $\left({ }^{4}\right)$ Institute of Terrestrial Magnetism, Ionosphere and Radiowave Propagation, \\ Russian Academy of Science, Russia
}

\begin{abstract}
A devastating earthquake of magnitude 6.9 occurred in Southern Italy on 23rd November 1980 in Irpinia-Basilicata area. Variations of different geochemical, atmospheric and ionospheric parameters and electromagnetic emissions were registered around the time of the Irpinia earthquake. The substantial progress reached in understanding the physics of the electromagnetic and thermal anomalies associated with the earthquake preparation process permitted us to create the Lithosphere-Atmosphere-Ionosphere (LAI) coupling model published recently. It shows that the observed effects are not independent but present the cause-consequence chain of physical processes and plasma-chemical reactions. We try to analyze the seismic data, radon emanation, hydrological anomalies, ground based ionosondes network, NOAA/AVHRR Thermal Infrared Irradiance (TIR) anomaly, Intercosmos-19 satellite topside sounding and VLF emissions data using the concept of the developed model and existing laboratory and largescale active experiments on air ionization. If the observed radon activity is really connected with the earthquake preparation process, all other variations of the atmosphere and ionosphere parameters can be explained as a consequence of the main physical process - air ionization by radon.
\end{abstract}

Key words lithosphere-atmosphere-ionosphere coupling - radon-ionization

\section{Introduction}

The Irpinia earthquake took place on 23rd November $1980\left(M_{S}=6.9\right)$ at $18 \mathrm{~h} 34 \mathrm{~m}$ UT. The normal slip with average value $61 \mathrm{~cm}$ along the fault occurred with strike orientation N18W. It

Mailing address: Dr. Sergey A. Pulinets, Instituto de Geofísica, Universidad Nacional Autónoma de México, Ciudad Universitaria, Del. Coyoacán, México D.F 04510; e-mail: pulse@geofisica.unam.mx was oriented parallel to the Apennines Mountains axis. The size of the earthquake source estimated by the aftershock activity was of the order 14×40 km (Deschamps and King, 1980). This earthquake was one of the strongest events in 20th century Italy. It caused the death of about 3000 people, total destruction of 15 towns and severe damage within a radius near $50 \mathrm{~km}$. Maybe for this reason it is one of the well studied strong seismic events where the rich dataset of different parameters including their variations before and after the earthquake was collected. The seismic data, focal mechanism and other seismological information were widely discussed in the special issue of Annali di Geofisica (Boschi et al., 1993) and in many 
dedicated publications (Bernard and Zollo, 1989). One can find the rich set of references on the papers devoted to Irpinia earthquake in Valensise (1993). Allegri et al. (1983) analyzed the radon and tiltmeter data before the Iripinia earthquake. Martinelli et al. (1999) analyzed the thermic springs and their relation with tectonic faults position in the Southern Italy. Italiano et al. (2000) from the geochemical data for the tectonic faults in Southern Apennines found possible magma intrusions from deep lithosphere. Esposito et al. (2001) demonstrated examples of hydrological anomalies around the time of Irpinia earthquake. Legen'ka et al. (1995) presented evidence of ionospheric anomaly development before the Irpinia earthquake. Ruzhin and Larkina (1996) registered the VLF noises and stimulated particles precipitation over the area of Irpinia earthquake preparation and in magnetically conjugated zones from onboard Intercosmos-19 satellite. Pulinets and Legen'ka (1997, 2003) suggested a similar magnetically conjugated effect in electron concentration variations and formation of the large scale ionospheric irregularity one day before the Irpinia earthquake using the topside sounding data from Intercosmos-19 satellite. Tramutoli et al. (2001) and Di Bello et al. (2004) analyzing several years of NOAA/AVHRR (Advanced Very High Resolution Radiometer on board NOAA - US National Oceanographic and Atmospheric Administration - satellites) satellite data in the same month of Irpinia earthquake occurrence detected TIR anomalies (never observed in seismically quiescent years) several days before the Irpinia earthquake not only in the epicentral zone but at distances corresponding to the radon measurements of Allegri et al. (1983) and estimations of the earthquake preparation area of Dobrovolsky et al. (1979).

The concept of the earthquake preparation area was developed by Dobrovolsky et al. (1979) using the calculations of elastic deformation of the Earth's crust. They obtained the logarithmic law connecting the size of the area with the specified level of deformation and the earthquake magnitude. Then they posed on this distribution the maximal distance from the epicenter of different kinds of anomalies registered before earthquake by different researchers.
These anomalies included changes in the ground resistivity, magnetic and gravitational fields, electric field anomalies, variations of $v_{p} / v_{s}$, electromagnetic emissions, geochemical anomalies, etc. It is very interesting that all these points occupied the line close to the $10^{-8}$ deformation level, and this dependence can be expressed as $R=10^{0.43 M}$ where $R$ is the size in kilometers, and $M$ the earthquake magnitude. The $R$ value was called the earthquake preparation area. Toutain and Baubron (1998) in their comprehensive review of around 170 publications on geochemical parameters registered around the time of strong earthquake put together the epicentral distance of the registered geochemical anomalies versus earthquake magnitude (see fig. 8 of their paper) using the data of the reviewed papers and the obtained distribution fits satisfactorily the curve of Dobrovolsky et al. (1979). The papers on statistical seismology describing the earthquake as a critical state (Bowman et al., 1998), area of activation of earthquake flow (Kossobokov et al., 2000), precursory seismic activation area (Rundle et al., 2000), cite the Dobrovolsky et al. (1979) result and show that their dependencies are in agreement with the Dobrovolsky formula. It means that this relationship has more fundamental meaning than simply elastic deformation on the level of $10^{-8}$.

We are now at a turning point where the skepticism of the end of 20th century is replaced by the realistic approach and reserved optimism connected with the recently developed techniques of middle-term and short-term prediction. And if the statistical seismology gives only the regions, so called «hot spots» of the expected earthquakes in the middle term perspective (Tiampo et al., 2002), the satellite technologies are able to answer on the three main questions of prediction: where? when? and how strong? (Pulinets and Boyarchuk, 2004; Bondur and Zverev, 2005; Pulinets, 2006). At present at least two directions show successes in understanding of underlying processes and produce some hope for short-term prediction - it is the statistical seismology and seismo-electromagnetic phenomena (Haya-kawa and Molchanov, 2002). We will concentrate on the last one because our results clearly show the electromagnetic nature of the 
observed phenomena few days before the Irpinia earthquake. The electromagnetic and thermal phenomena observed as on the ground surface so in the near-Earth plasma few days before the seismic shock (Pulinets et al., 1994; Chmyrev et al., 1997; Molchanov and Hayakawa, 1998; Molchanov et al., 1998; Pulinets, 1998; Liu et al., 2000, 2002, 2004; Biagi et al., 2001; Tramutoli et al., 2001; Chuo et al., 2002; Di Bello et al., 2004; Filizzola et al., 2004) recently obtained their explanation within the frame of the developed physical model of seismo-ionospheric coupling (Pulinets et al., 2000, 2002; Pulinets and Boyarchuk, 2004). The main advantage of the model is that most of the observed phenomena can be united in the chain of interconnected physical and chemical processes. Within the frame of the model the revealed interconnections produce the new view on the old data.

The purpose of physics is explanation of observed natural phenomena. We hope that the present paper will help us to understand why variations of different atmosphere and ionosphere parameters are observed before earthquakes, and why we can hope to use them in the future for probably short-term earthquake warning.

\section{The physical model}

Conditionally the model proposed by $\mathrm{Pu}-$ linets et al. (1998a, 2000, 2002, 2006) and Pulinets and Boyarchuk (2004) can be divided into two branches - atmospheric and ionospheric. The first explains the anomalies observed in the boundary layer of atmosphere, and the second the ionospheric anomalies observed before the earthquakes.

Both of them have a common origin - the Earth's natural radioactivity, and the main physical process - the air ionization produced by the radon emanating from the Earth's crust. Radon, the heavy noble gas, is a product of radium decay inside the Earth; it is emanating continuously all over the world and sometimes presents serious problem for human health. The main problem which indoor radon creates is lung cancer (Krewski et al., 2002). The intensity of radon emanation is higher near active tectonic faults
(King et al., 1993; King, 1996). It was detected that before earthquakes specific variations of radon flux are observed (Khilyuk et al., 2000). Actually, the radon records are very noisy because of many factors influencing radon emanation intensity including rains, atmospheric pressure etc., but the new techniques were developed recently permitting us to reveal from the records the variations associated only with the seismic activity (Belyaev, 2001; Zmazek et al., 2005). The second and the most important question is: do specific radon variations appear for every earthquake? It is difficult to make the positive answer at present, it is still the subject of dispute but carefully organized measurements in Turkey (Inan, 2005) and Izrael (Zafrir et al., 2005) give very promising results demonstrating the radon concentration increase even for very small shocks (as happens in Israel for earthquakes with magnitudes lower than 3). Indirect evidence of radon variations before earthquakes is the specific character of atmospheric variations before earthquakes (Dunajecka and Pulinets, 2005) which can be explained only by the air ionization which, in turn can be produced only by radon.

High energy (near $6 \mathrm{MeV}$ ) alpha particles emitted by radon produce the air ionization. Under action of an ionizing radiation in the atmosphere in an initial stage a large amount of $\mathrm{O}_{2}^{+}$ ions is formed both as a result of direct ionization, and as a result of charge exchange between an initial ion $\mathrm{N}_{2}{ }^{+}$and electrons, which fast adhere to atoms of oxygen, since the oxygen has a significant energy of an affinity to electrons, forming the negative ions $\mathrm{O}^{-}$and $\mathrm{O}_{2}^{-}$. As a result of fast ion-molecular reactions during the interval of order $10^{-7} \mathrm{~s}$ the main elementary tropospheric ions will be formed: $\mathrm{O}^{-}, \mathrm{O}_{2}^{-}, \mathrm{NO}_{2}^{-}, \mathrm{NO}_{3}^{-}$, $\mathrm{CO}_{3}{ }^{-}$and $\mathrm{O}_{2}{ }^{+}, \mathrm{NO}^{+}, \mathrm{H}_{3} \mathrm{O}^{+}$. The large amount of water vapor molecules contained in the troposphere $\left(\sim 10^{17} \mathrm{~cm}^{-3}\right)$, having a noticeable dipole moment $p=1.87 \mathrm{D}$, leads to hydration of elementary ions and formation of ion complexes of a type $\mathrm{NO}_{2} \cdot \cdot\left(\mathrm{H}_{2} \mathrm{O}\right)_{n}$ and $\mathrm{NO}_{3}{ }^{-} \cdot\left(\mathrm{H}_{2} \mathrm{O}\right)_{n}, \mathrm{NO}_{3}{ }^{-}$. $\cdot\left(\mathrm{HNO}_{3}\right)_{n}\left(\mathrm{H}_{2} \mathrm{O}\right)_{m}$ and $\mathrm{O}_{2}{ }^{+} \cdot\left(\mathrm{H}_{2} \mathrm{O}\right)_{n}, \mathrm{NO}^{+} \cdot\left(\mathrm{H}_{2} \mathrm{O}\right)_{n}$, $\mathrm{H}^{+} \cdot\left(\mathrm{H}_{2} \mathrm{O}\right)_{m}$ and $\mathrm{H}_{3} \mathrm{O}^{+} \cdot\left(\mathrm{H}_{2} \mathrm{O}\right)_{n}$ that happens rather fast. The ions $\mathrm{NO}_{3}{ }^{-} \cdot\left(\mathrm{H}_{2} \mathrm{O}\right)_{n}, \mathrm{NO}_{3}{ }^{-} \cdot\left(\mathrm{HNO}_{3}\right)_{n}$. $\cdot\left(\mathrm{H}_{2} \mathrm{O}\right)_{m}$ and $\mathrm{H}_{3} \mathrm{O}^{+} \cdot\left(\mathrm{H}_{2} \mathrm{O}\right)_{m}$ could be regarded as the main ions of troposphere with a high level of probability. The average time of life of these 
ions reaches 30-40 min and more in usual conditions (Smirnov, 1992). The process of formation of large ion clusters has been known for a long time and proved in laboratory experiments with thoron injection in chamber with pure air (Bricard et al., 1968). It was recently supported by different publications describing the process of formation of large ion clusters of aerosol size under action of cosmic rays and natural radiation (radon) (Wilding and Harrison, 2005). So we can consider the process of aerosol formation due to ionization well established. Our model calculations show that the concentration of charged ion clusters as a result of radon ionization can reach $10^{5}-10^{6} \mathrm{~cm}^{-3}$ (Pulinets et al., 2000).

The chemical reaction of ions hydration is effectively water condensation on ions accompanied by the release of the latent heat of evaporation (Timofeev et al., 2003). The growth of particles due to water molecules attachment to ions is calculated by Wilding and Harrison (2005), and more detailed ion kinetics is considered by Boyarchuk et al. (2005). As a final result of the hydration we should observe the changes in air temperature (due to latent heat release) and humidity (due to water vapor condensation on ions). Silva and Claro (2005) found a 95\% correlation between the changes of atmosphere parameters and the fluxes of radon and its products. Dunajecka and Pulinets (2005) registered the variations of air humidity and temperature around the time of major earthquakes in Mexico. Pulinets et al. (2006) calculated the changes in air relative humidity under action of radon ionization and found that using the experimental values of radon emission it is possible to change the air humidity from $100 \%$ up to $30 \%$ during $10 \mathrm{~h}$.

Finalizing the description of the atmospheric branch of our model, we can state that as a final result of the increased ionization level before earthquakes the changes in the air relative humidity (decrease) and near ground air temperature (increase) should be observed. In the present state of our model we are able to calculate the concentration of the forming ion clusters and changes in air humidity. The total thermal balance model is under development.

The appearance of the heavy charged ion clusters in the troposphere leads to the modifica- tion of the vertical electric field which is the part of the global electric circuit providing the electrodynamic coupling between the ground and the ionosphere (Roble and Tzur, 1986). Slight modification of the atmospheric electric field in the near ground layer of the troposphere happens everywhere and is named the «electrode effec» (Hoppel, 1967; Boyarchuk et al., 1997). The difference between the seismic and non-seismic areas is that the radon emanation in the vicinity of tectonic fault is higher, producing the higher level of air ionization (King et al., 1993). In addition the radon flux intensity increases before a strong earthquake within the area of earthquake preparation (Khilyuk et al., 2000). The effect of the additional number of aerosols on the atmospheric electric field is calculated in Boyarchuk et al. (1998) and more recently in Boyarchuk et al. (2005). Rulenko (2000), in his review of anomalous electric field variations before earthquakes, shows examples of variations within the range of several $\mathrm{kV} / \mathrm{m}$. The most recent results of anomalous electric field registration before earthquakes are found in Smirnov (2005). Such variations are not unique for the earthquakes case, similar electric field jumps were registered, for example in the morning fog (Mühleisen, 1958).

The charged particles of dusty atmospheric plasma (Pulinets et al., 2002) will be accelerated in the strong anomalous electric field and generate electromagnetic emission within the wide frequency band. We strongly believe that ELF-VLF electromagnetic emissions registered before the seismic shocks (Frazer-Smith et al., 1990) are the result not of some underground processes very difficult to explain, but the plasma instabilities in the near ground dusty atmospheric plasma. This will be the subject of a separate paper. The ELF-VLF emission can also be produced by coronal discharges from cutting edges under the action of anomalous electric field as proposed by Bardakov et al. (2004).

The electric field penetration into the ionosphere was calculated in the series of publications of Kim et al. $(1994,1996)$ and in concise form presented in Pulinets et al. (2000). The calculations are based on the modified formulation of Park and Dejnakarintra (1973) who estimated the penetration of the thunderstorm cloud electric field into the ionosphere. This formulation 
was checked by many authors (Tzur and Roble, 1985; Rodger et al., 1998; McCormick et al., 2002) and was found to be correct. Instead of the point source (Park and Dejnakarintra, 1973) Kim and Hegai (1997) used the finite size of the electric field source which increased the electric field penetration effectiveness. The used electric field source geometry was as cylindrically symmetrical (Kim et al., 1994) as elongated (Pulinets et al., 1998b). It was demonstrated how important the size of the electric field source is. For example, in Pulinets et al. (1998b) it was shown that for a large elongated source presented by the Andes Mountains, even an additional $65 \mathrm{~V} / \mathrm{m}$ is enough to cause the noticeable effect in the ionosphere. The size of the electric field source is directly related to the size of the earthquake preparation zone (Dobrovolsky et al., 1979) and will be discussed below. Here we will only comment that from the model estimations of Pulinets et al. (2000) the minimal size of the electric field source (for the electric field intensity near $1 \mathrm{kV} / \mathrm{m}$ on the ground surface) should be of order of $200 \mathrm{~km}$ to cause a noticeable effect within the ionosphere. Such source will create in the ionosphere (E-layer) the electric field perpendicular to the geomagnetic field lines in the order of $1 \mathrm{mV} / \mathrm{m}$ which is sufficient to create the ionospheric irregularities due to particles $\boldsymbol{E} \times \boldsymbol{B}$ drift. Due to high electric conductivity along the geomagnetic field lines the anomalous electric field will map into the upper layers of the ionosphere and magnetosphere creating the irregularities of electron concentration experimentally registered by satellites $(\mathrm{Pu}-$ linets and Legen'ka, 2003; Parrot, 2005).

We will summarize the model by a short description indicating what it is able to estimate quantitatively at present. Taking the level of ionization the model gives possibility to estimate the concentration of the charged aerosols in the near ground layer of atmosphere as a result of ionization, to calculate the anomalous electric field value, to calculate the changes in air relative humidity as a result of the ionization process, to calculate the frequency of electromagnetic emission in VHF frequency band emitted by neutral clusters, to calculate the variations of electron concentration, at altitudes of $D, E, F$ layers of the ionosphere and in the magnetosphere at the lev- els 2000 and $3000 \mathrm{~km}$, it explains the formation of sporadic $E$-layers before earthquakes due to anomalous electric field effect. Our future plans - to derive the physical mechanism for ELFVLF emissions observed on the ground level before earthquakes, and to estimated the changes in the air temperature observed by ground based measurements and by satellites.

Let us try to trace how this model works in the case of the Irpinia earthquake using the data of ground based and satellite observation.

\section{Earthquake preparation area}

The size of the area which can be identified with the process of the earthquake preparation has always been the subject of severe discussions. We will not enter in this discussion again but bring the obvious facts which come directly both from recent seismology studies, and outside of seismology. Tiampo et al. (2002) elaborated statistical technology which permits them to predict the position of future earthquake epicenters using the information on the previous seismic activity. This gave them possibility to indicate correctly the places of 14 from 16 recent earthquakes in California. They use information on seismic activity across the large areas, much larger than the size of the source of the future earthquake. It means that the seismic activity at the large areas has the cause-effect relationship with the future earthquake in the given point. Other indications on the size of the earthquake preparation area come form geochemistry and from satellite measurements of thermal anomalies before the earthquakes. Toutain and Baubron (1998) demonstrated the distribution of pre-earthquake registered geochemical anomalies (mainly the radon) which follows the Dobrovolsky formula described above. As shown by King et al. (1993) and Sengupta et al. (2005) the radon anomalies are concentrated mainly along the active tectonic faults. Using the model presented above one should expect the temperature increase along the active tectonic faults before the strong earthquakes. And this is just a case. The papers (Tramutoli et al., 2001, 2005; Tronin et al., 2004; Dey and Singh, 2003; Ouzounov and Freund, 2004) and many others (their quantity grows in exponential law) 
show the increase in the temperature over the tectonic faults a few days before the seismic shock. And what is more important is that the size of the thermal anomalies registered by the satellites is enormous, demonstrating that the area of the earthquake preparation is large. This fact cannot be either neglected, either concealed. If our conception is correct, we can make the reverse pro-

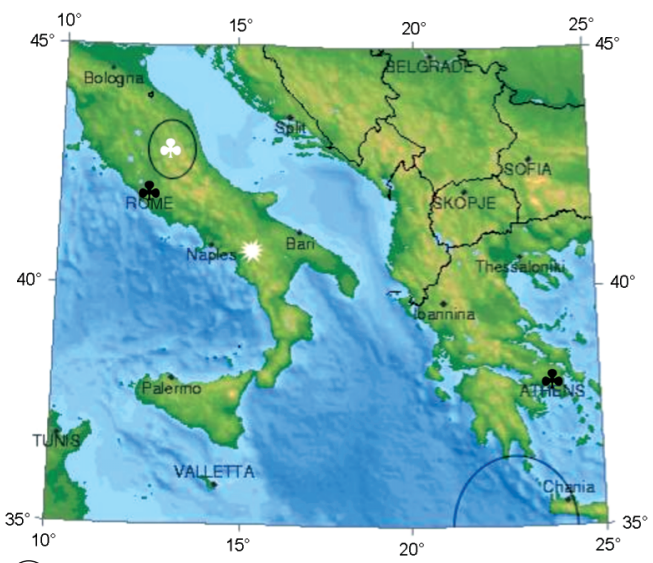

(a)

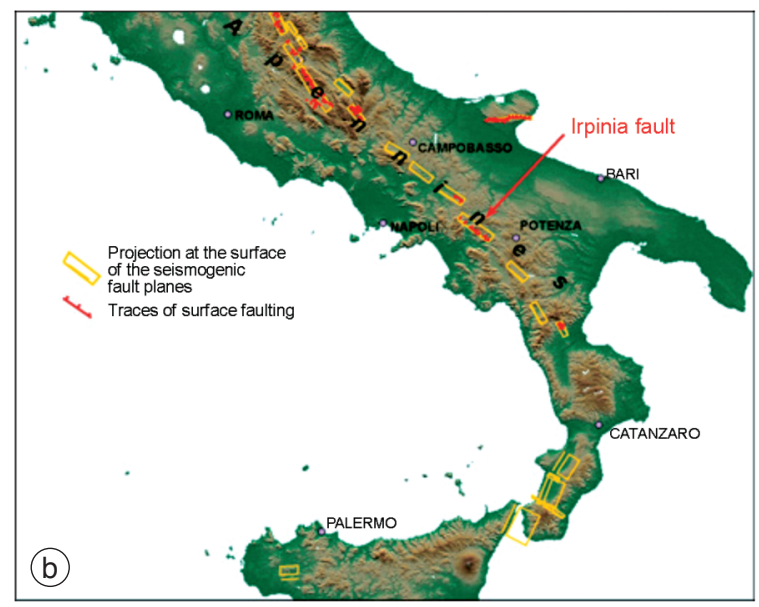

Fig. 1a,b. a) The map of Central Mediterranean. Black indicate positions of ionosondes at Rome and Athens, white indicates the Rieti radon monitoring station. Star indicates the position of Irpinia earthquake epicenter. Ovals indicate the position of ionospheric anomalies registered by Intercosmos-19 satellite. b) Configuration of active tectonic faults at Apennines Peninsula.

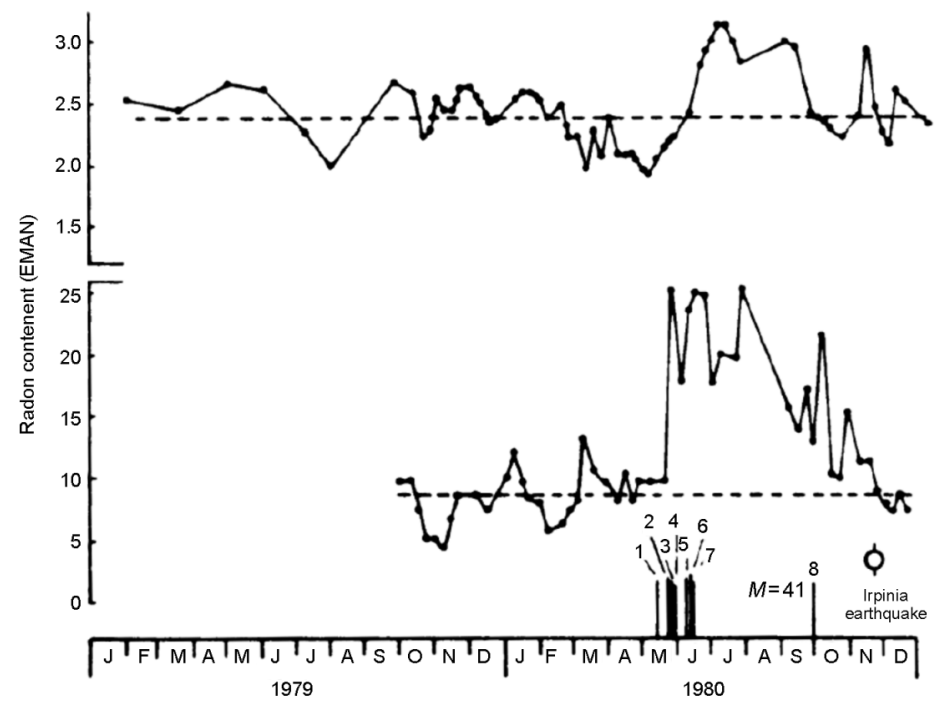

Fig. 2. Radon anomalies registered at Rieti (upper panel) and Rome (bottom panel) stations during period 1979-1980 (after Alegri et al., 1983). 
cedure: from the configuration of the thermal anomalies observed by the satellites to determine the areas of increased radon emanation. And just this conception permits us to interpret all the observed anomalies before the Irpinia earthquake within the frame of the common physical mechanism.

We will analyze the radon variations, satellite registered TIR anomalies, ground based ionosondes data, ionospheric variations registered by the Intercosmos-19 satellite. The measurement sites and anomalies position are shown in fig. 1a,b.

\section{Radon anomalies registered before the Irpinia earthquake}

Figure 2 demonstrates the temporal development of the radon anomalies registered on two stations (Rieti and Rome) at distances of 270 and $250 \mathrm{~km}$ respectively from the epicenter. One can see the sharp increase in the radon flux associated with the seismic swarm started in the middle of May 1980. Both stations demonstrate a similar behavior - long duration maximum, then the essential drop is registered associated with the foreshock at the end of September and the second period of the activity with gradual diminishing of the radon flux up to the background level close to the time of the Irpinia earthquake. This dynamics is in good agreement with the precursory radon variations reported by other researchers (Scholz, 1990; Khiluk et al., 2000; Inan, 2005). According to the physical model discussed above, the radon anomaly registered at a distance $250 \mathrm{~km}$ from the epicenter (what gives the area of $500 \mathrm{~km}$ in diameter) lets us expect the effects in the ionosphere.

It should be noted that the correlation of the radon activity variations and the electron concentration registered in the ionosphere close to the radon monitoring point was revealed recently (Pulinets et al., 1997, 1999).

\section{TIR anomalies before the Irpinia earthquake}

Tramutoli et al. (2001) and Di Bello et al. (2004) made very careful analysis of the TIR anomalies recorded before the Irpinia earthquake. They performed a preliminary multiyear analysis of co-located NOAA/AVHRR infrared data to obtain the local background values (in terms of time-average and standard deviation) expected for the area (about $600 \mathrm{~km}$ radius) around the Irpinia earthquake epicenter in similar observational conditions (November, late afternoon). TIR signal exceeding the expected value by at least one standard deviation were considered possible thermal anomalies. This robust technique revealed the temporal and spatial behavior of the TIR anomalies before the Irpinia earthquake in the epicentral area and in the areas distant from the epicenter. Figure 3 demonstrates the activation, during November 1980, of the whole tectonic fault along the Apennines Peninsula expressed in the form of monthly average of thermal signal excesses (compare with fig. 1b). Figure 4a,b demonstrates the difference in the temporal dynamics of the near epicenter and far zones (near $250 \mathrm{~km}$

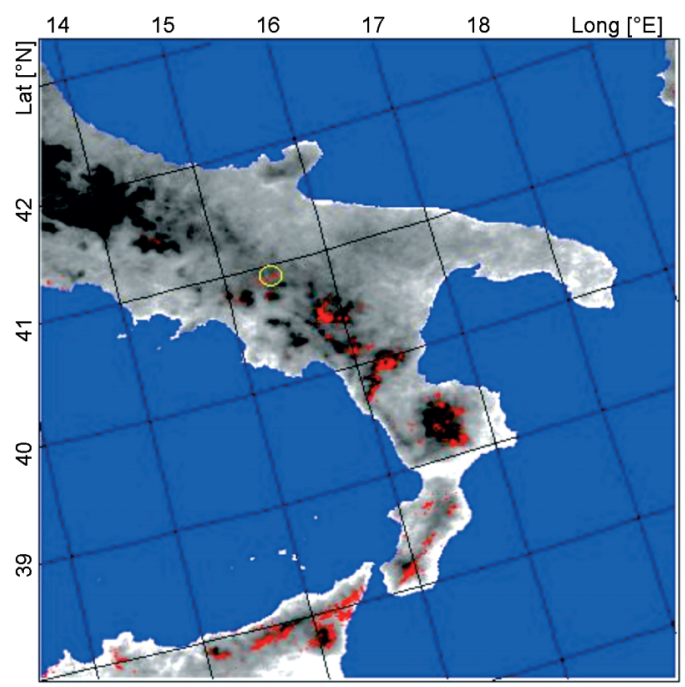

Fig. 3. Irpinia-Basilicata earthquake $\left(M_{S}=6.9\right.$, November, $23,1980,7.32$ p.m.): analysis in the temporal domain over the extended study area for November 1980. Thermally anomalous area is depicted in red tones. The circle represents the epicentral zone (from Tramutoli et al., 2001). 
from the epicenter) within the interval a few days before the seismic shock. The large scale of the thermal anomalies testifies to the atmosphere modification over a large area which is very important for the anomalous electric field generation, and for its penetration into the ionosphere.
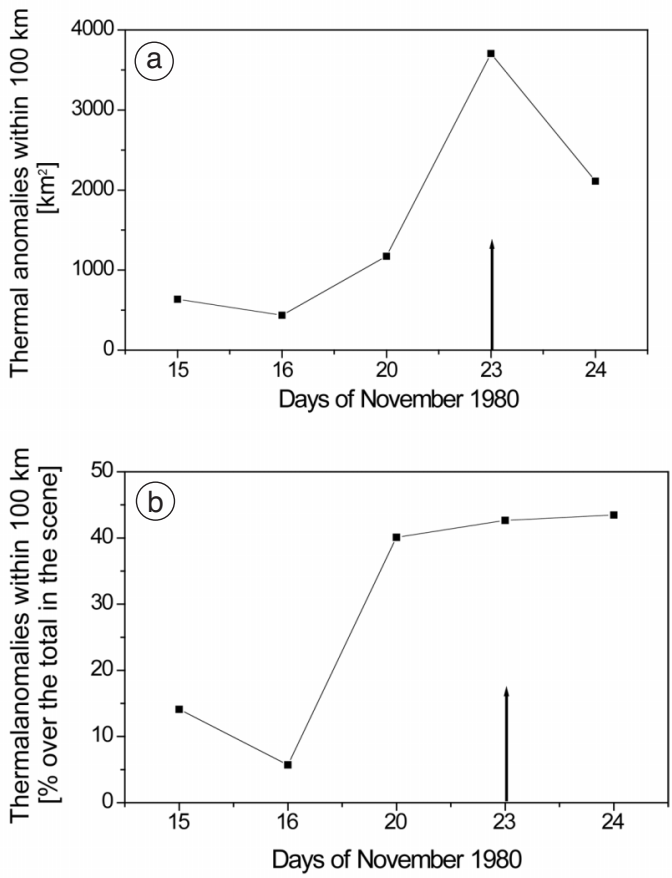

Fig. 4a,b. Irpinia-Basilicata earthquake $\left(M_{S}=6.9\right.$, November, 23, 1980, 7.32 p.m.): a) temporal evolution of the extension of the thermally anomalous area around the epicenter. The extension of thermal anomalies (expressed in AVHRR pixel number) occurring in a circle of $100 \mathrm{~km}$ of radius around the epicenter, is plotted few days before and after the earthquake occurrence (black arrow). Modified from Tramutoli et al. (2001). b) Comparative analysis of the temporal evolution of the extension of thermal anomalies within and far away from the epicentral zone. The percentage (over the total in the scene) of thermal anomalies falling in a circle of $100 \mathrm{~km}$ of radius around the epicenter, is plotted few days before and after the earthquake occurrence (black arrow). Modified from Tramutoli et al. (2001).

\section{Revealing the ionospheric anomaly before the Irpinia earthquake}

Kouris et al. (2001), analyzing the data of Rome ionospheric station for the period of the Irpinia earthquake (November 1980), did not find anything suspicious and came to the conclusion that there no indications on the ionospheric precursors of Irpinia earthquake in the Rome data. Before analyzing the ground-based data we will look first at the data of topside sounding from Intercosmos-19 satellite which was in orbit in 1979-1980.

\subsection{Satellite mapping}

The description of the topside sounder installed onboard the Intercosmos-19 satellite can be found in Pulinets (1989), and the procedure of the ionospheric mapping - in Pulinets and Legen'ka (2003). The satellite mapping yields a latitudinal-longitudinal distribution of the ionospheric disturbance over the area of the Irpinia earthquake. For mapping of the critical frequency deviation $\Delta f_{o} F 2(\varphi, \lambda)$ the available satellite data were used. Around the time of the Irpinia earthquake the Intercosmos-19 satellite passed over the epicenter at $0304 \mathrm{~h} \mathrm{LT}$ for $\Delta t \approx-112$, $-87,-64,-42,-40$, and $+9 \mathrm{~h}$ in relation to the main shock instant; and at $18-19 \mathrm{~h} \mathrm{LT}$ for $\Delta t \approx$ $\approx-120,-96,-72$, and $-1.39 \mathrm{~h}$ accordingly. The anomalous decrease and increase of $f_{o} F 2\left(《 f^{-} »\right.$ and $\left\langle f^{+} \gg\right)$ were observed during the early morning hours and evening hours, respectively. The maps of $\Delta f_{o} F 2(\varphi, \lambda)$ using the data of November 18-19 were taken as the quiescent background. The maps of $\Delta f_{o} F 2(\varphi, \lambda)$ for morning hours were plotted for three different time intervals: $\Delta t \approx-64 ;-40 \ldots-42.5$, and $+6 \ldots+8$ h (fig. $5)$. One can see that the «cloud» of a decreased density gradually began to be formed already 2.5 days $(\Delta t \approx-64 \mathrm{~h}$ ) ahead of the main shock, but in the region displaced by $\sim 10^{\circ}$ in both latitude and longitude to the south-east of the epicenter. Later, at $\Delta t \approx-40 \ldots-42 \mathrm{~h}$, this «cloud» was displaced toward the epicenter and «spread» in the northwest direction. Roughly 6$8 \mathrm{~h}$ after the main shock, the state of the ionosphere in the epicenter region was stabilized. 

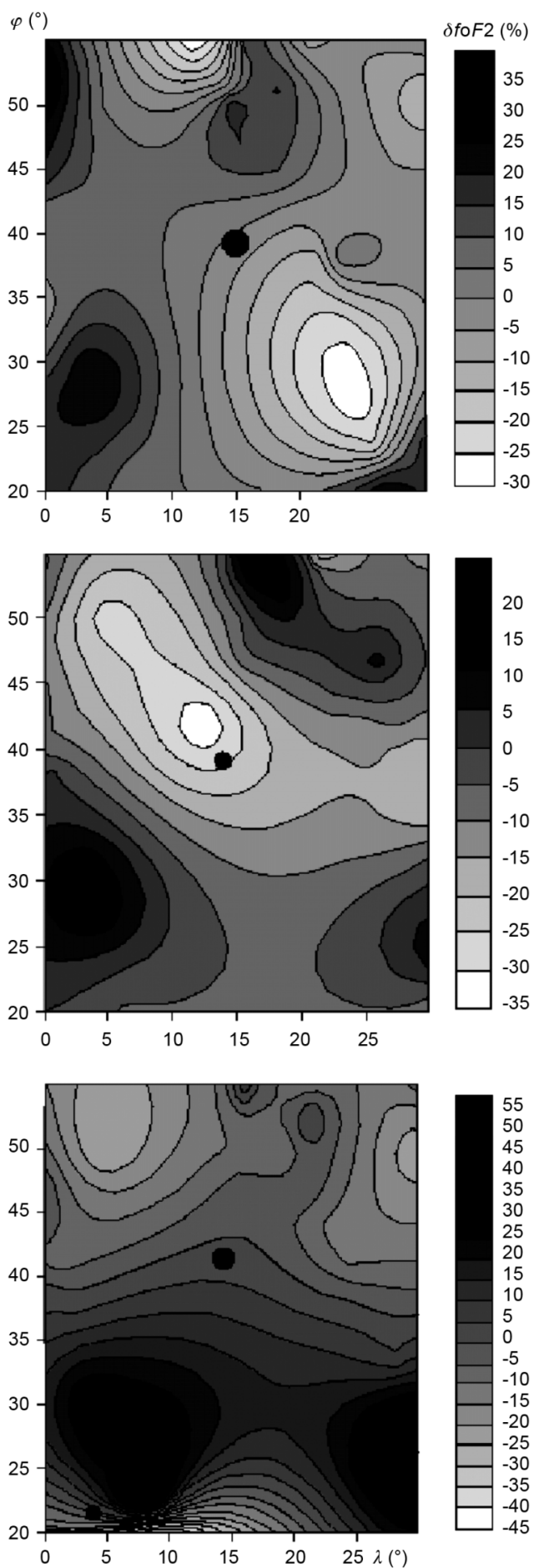

Fig. 5. Dynamics of the modified region in the ionosphere $-64,-42$ and $+9 \mathrm{~h}$ in relation to the Irpinia earthquake seismic shock moment by the data of Intercosmos-19 topside sounding.

As one can see, the effects within the ionosphere over the area of Irpinia earthquake were quite significant in size $\left(20^{\circ}-30^{\circ}\right.$ in latitude and longitude modified region within the ionosphere) and in amplitude $\pm 30 \%$ for evening and morning hours.

\subsection{Modification of the altitude distribution of the electron concentration}

One of the effective tools to distinguish the variations in the ionosphere caused by anomalous electric field generated around the time of strong earthquakes is the value of the scale height of the topside profile of the electron concentration. It was detected (Pulinets et al., 2003) that the scale height, and consequently semithickness of the layer increases over the area of earthquake preparation. The profile semithickness can be obtained from the developed empirical approximation of the topside vertical profile of the electron concentration (Depuev and Pulinets, 2004). The topside profile is approximated by the Epstein function

$$
N(z)=4.0 * \frac{N_{0} \exp \left(\frac{z}{B_{2 u}}\right)}{\left(1+\exp \left(\frac{z}{B_{2 u}}\right)\right)^{2}}
$$

where $B_{2 u}$ characterizes the topside layer thickness and changes linearly with the height $B_{2 u}=$ $=B_{0}+k \times z, z=h-h_{\max }$.

In the case of the Irpinia earthquake the $B_{2 u}$ was calculated for the topside profiles corresponding to the satellite passes over the epicentral area, for the ionograms when satellite was in the closest approach to the impending epicenter position. The results are presented in fig. 6 . The figure demonstrated the increase of the topside profile semithickness up to $\sim 80 \mathrm{~km}$. As shown in Pulinets et al. (2003) such increase 


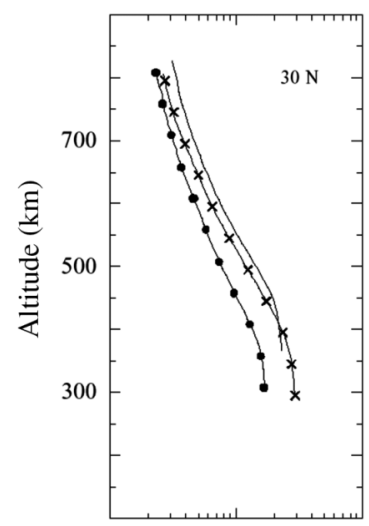

$\begin{array}{lllllll}2 & 3 & 5 & 10^{5} & 2 & 3 & 5\end{array}$

Electron density $\left(\mathrm{cm}^{-3}\right)$

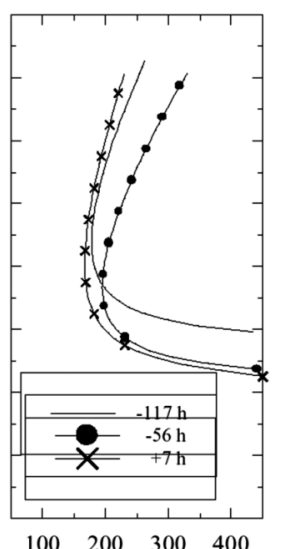

Height scale $(\mathrm{km})$

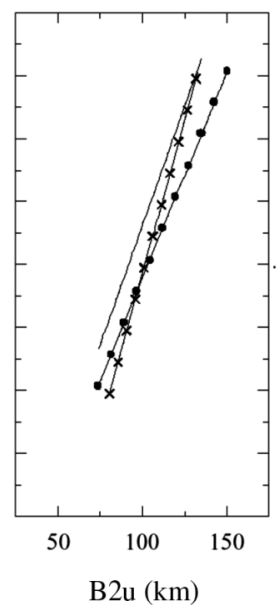

Fig. 6. Topside profiles (left), height scale (middle) and semithickness (right) for the period of the Irpinia earthquake in Central Italy, November, 1980.

can be interpreted as the mean ion mass drop. Simultaneously one can observe the rising of the $F 2$ layer (peak height increase $\sim 100 \mathrm{~km}$ ).

\subsection{Conjugated effects}

It was shown earlier using the data of Intercosmos-19 satellite around the time of the Irpinia earthquake (Pulinets and Legen'ka, 1997; Ruzhin et al., 1998) that ionospheric effects might appear not only in the epicenter region, but also in the magnetically conjugated point in the opposite hemisphere. Combining the Inter-kosmos-19 satellite and ground based ionosondes, we succeeded in constructing a map $\Delta f_{o} F 2(\varphi, \lambda)$ for the morning sector at $\Delta t \approx-64 \mathrm{~h}$ in the entire region of latitudes from $60^{\circ} \mathrm{N}$ to $60^{\circ} \mathrm{S}$, i.e. including the magnetically conjugated region (fig. 7). The latitudinal cross-section of the critical frequency deviation for the passes when conjugated effect was observed is presented in fig. 8. As one can see from the figure the positive deviation was observed during evening hours and the negative one before sunrise.

Intercosmos-19 satellite was the complex geophysical observatory and its payload contained the devices of different destination. A multichannel VLF receiver registered the VLF
$4540353025201510500 \quad-5-10-15-20-25-30-35-40$ $\delta f o F 2, \%(p r-q) 100 / q, \%(21.11 .80) \Delta t=-64$ h 03-04 h LT

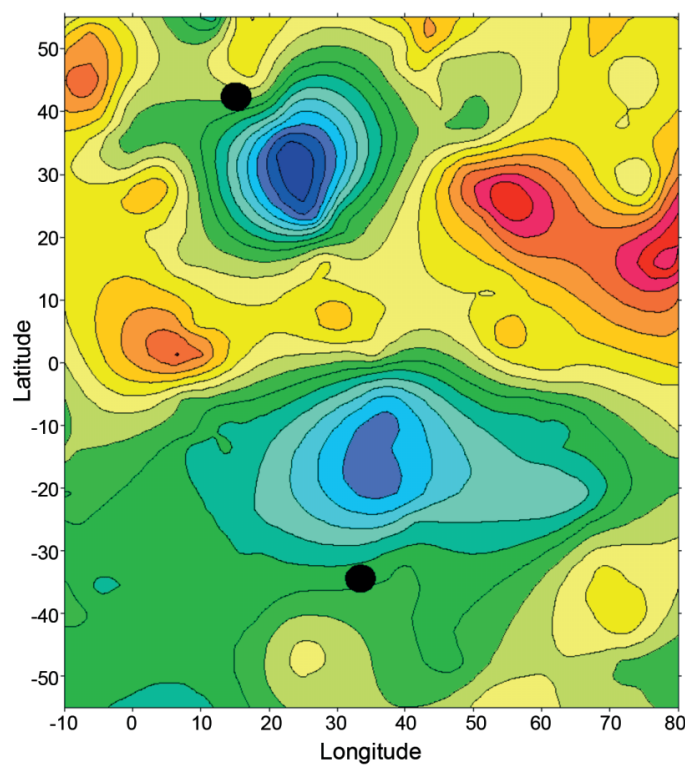

Fig. 7. Formation the conjugated modified area in the Southern Hemisphere before the Irpinia earthquake 23rd November 1980, $M=6.9$. Data from Intercomos-19 satellite topside sounding. 
emissions simultaneously with ionosonde, and also detected the conjugated effects in anomalous VLF emissions associated with the Irpinia earthquake (Ruzhin and Larkina, 1996; Ruzhin et al., 1998). The satellite orbits where both the ionospheric and VLF anomalies were registered are presented in fig. 8 (Pulinets and Legen'ka, 1997). The explanation of the VLF effect associated with the earthquakes can be found in $\mathrm{Pu}-$ linets and Boyarchuk (2004).

The registered VLF emissions for the case of Irpinia earthquake are in good correspondence with the described earlier and statistically confirmed results on the VLF emissions measurements before the strong earthquakes (Larkina $e t$ al., 1989). Taking into account that they are measured on the same parts of orbits as the ionospheric anomalies, we obtain confirmation that the observed ionospheric anomalies are also of seismogenic origin. The conjugate effect observed both in VLF emission and ionospheric density showed that the whole magnetospheric tube loaned onto the earthquake preparation area is modified. The effect of modification is observed before the seismic shock and disappears after it.

\subsection{Ground based data analysis}

If we have such significant effects registered by a spaceborne ionosonde, why was nothing observed by the ground based vertical sounding? It seems that such a situation is impossible. Let us return to the ground ionosonde data. Can we really not detect anything as claimed by Kouris
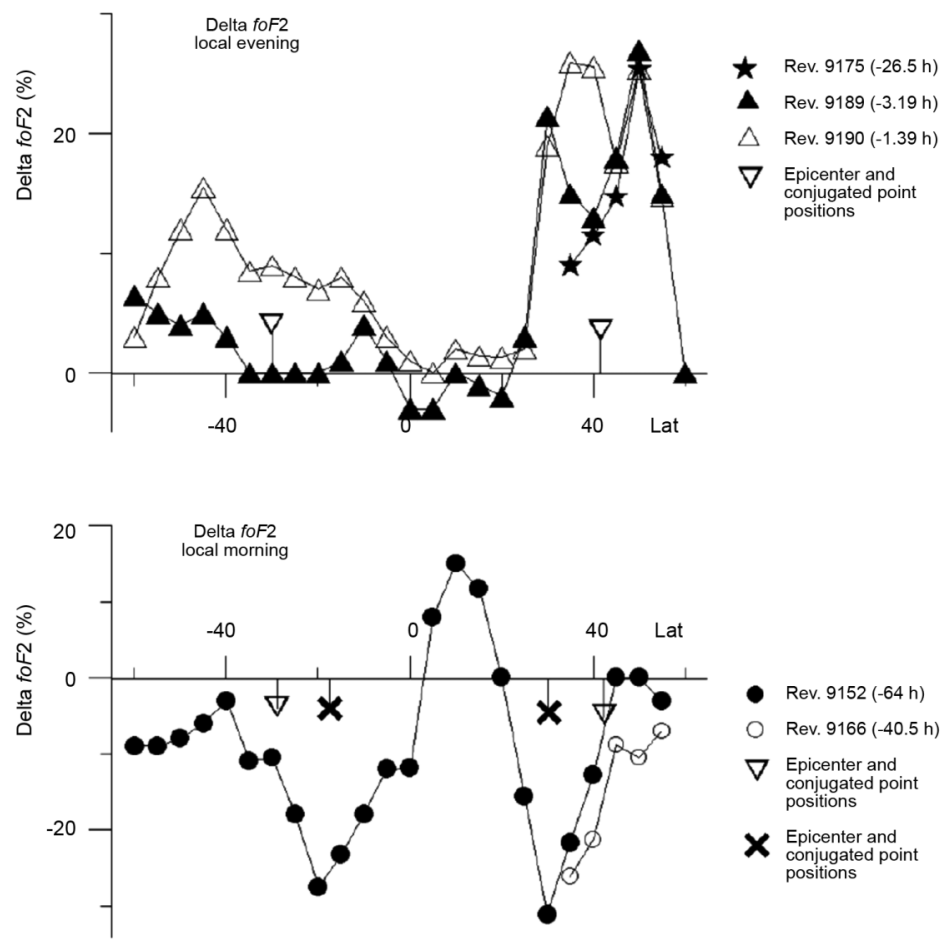

\footnotetext{
- Rev. 9152 (-64 h)

Rev. 9166 (-40.5 h)

$\nabla$ Epicenter and conjugated point positions

X Epicenter and conjugated point positions
}

Fig. 8. Deviation of the critical frequency $\triangle f o F 2$ for evening (upper panel) and early morning hours of local time for the passes of Intercosmos-19 satellite over Irpinia earthquake epicentral area and magnetically conjugated area. 


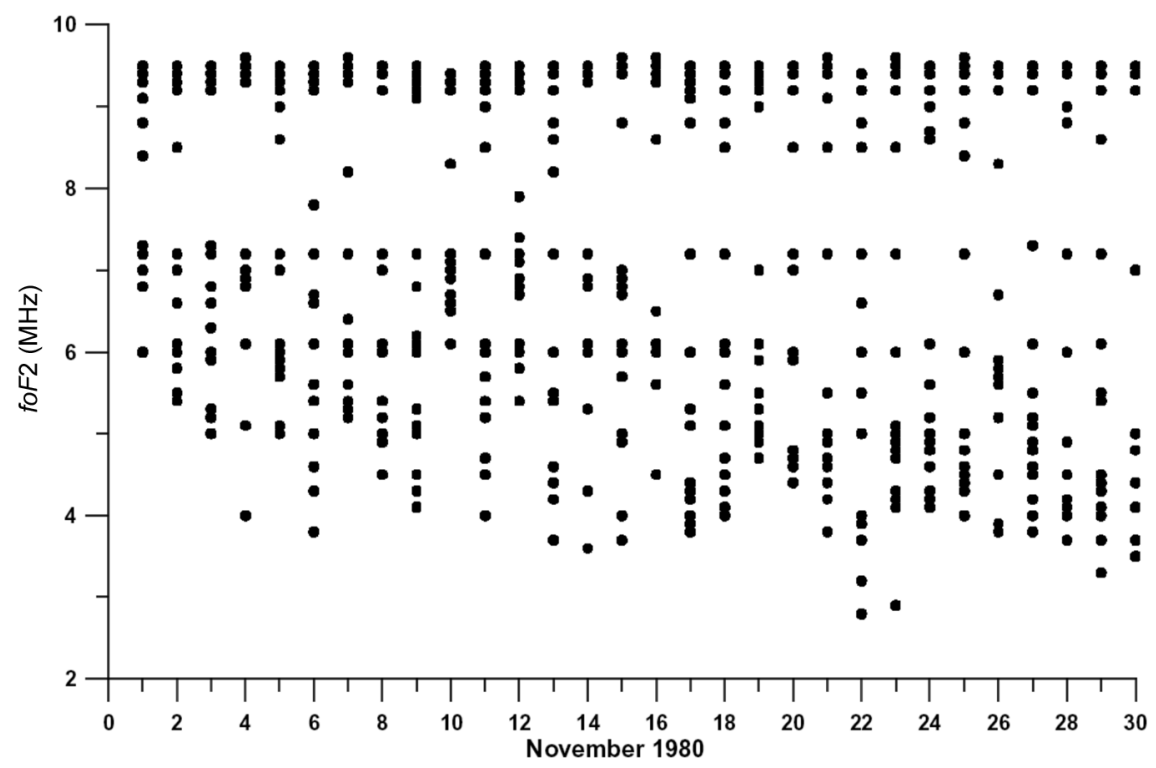

Fig. 9. Scattered plot for the critical frequency $f o F 2$ for November 1980 (Athens ionospheric station).

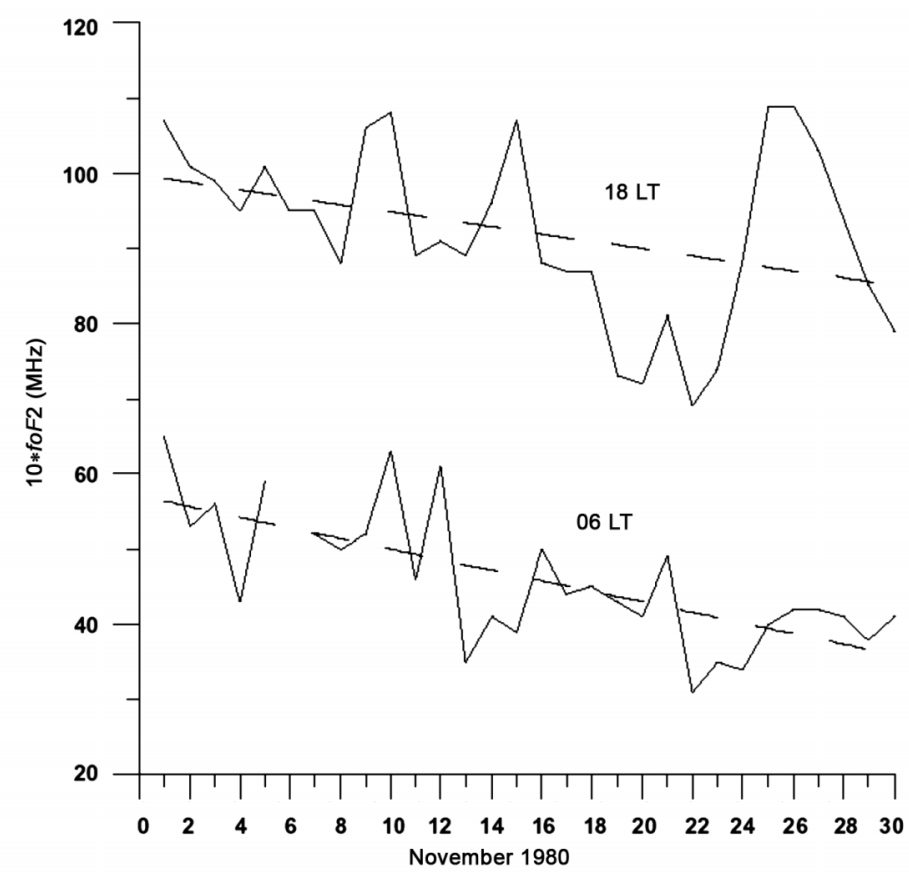

Fig. 10. Critical frequency for 06:00 LT and 18:00 LT for November 1980 (Rome ionospheric station). Dashed lines show the seasonal trend of the critical frequency. 
et al. (2001)? According to the presented satellite data (fig. 8) and our theoretical model, the effect in the ionosphere is shifted from the epicenter along the field lines, i.e. to the south-east. What does it mean? That maybe some ionospheric station to the south-east from epicenter will «feel» the process of the Irpinia earthquake preparation better. Fortunately, there was Athens ionospheric station working, which is situated just in the necessary direction. Let us compare the data from Rome and Athens. Taking into account that both stations are quite far from the maximum magnitude area shown by the satellite (fig. 1a), we cannot expect very pronounced variations, nevertheless both of them show spe- cific variations one day before the seismic shock, i.e. 22 November. It is expressed in the fact that both stations demonstrate the extreme values for the whole month of November, especially the Athens station. Figure 9 shows the scatter diagram where all the data of the critical frequency for November 1980 are shown for the Athens station. One can see the minimum demonstrated on 22 and 23 of November. It is important to note, that all play is going on the background of the strong seasonal negative gradient (the electron density sharply decreases during November due to season change). Nevertheless, the days 22 and 23 show the absolute minimum for the whole month. Figures 10 and 11
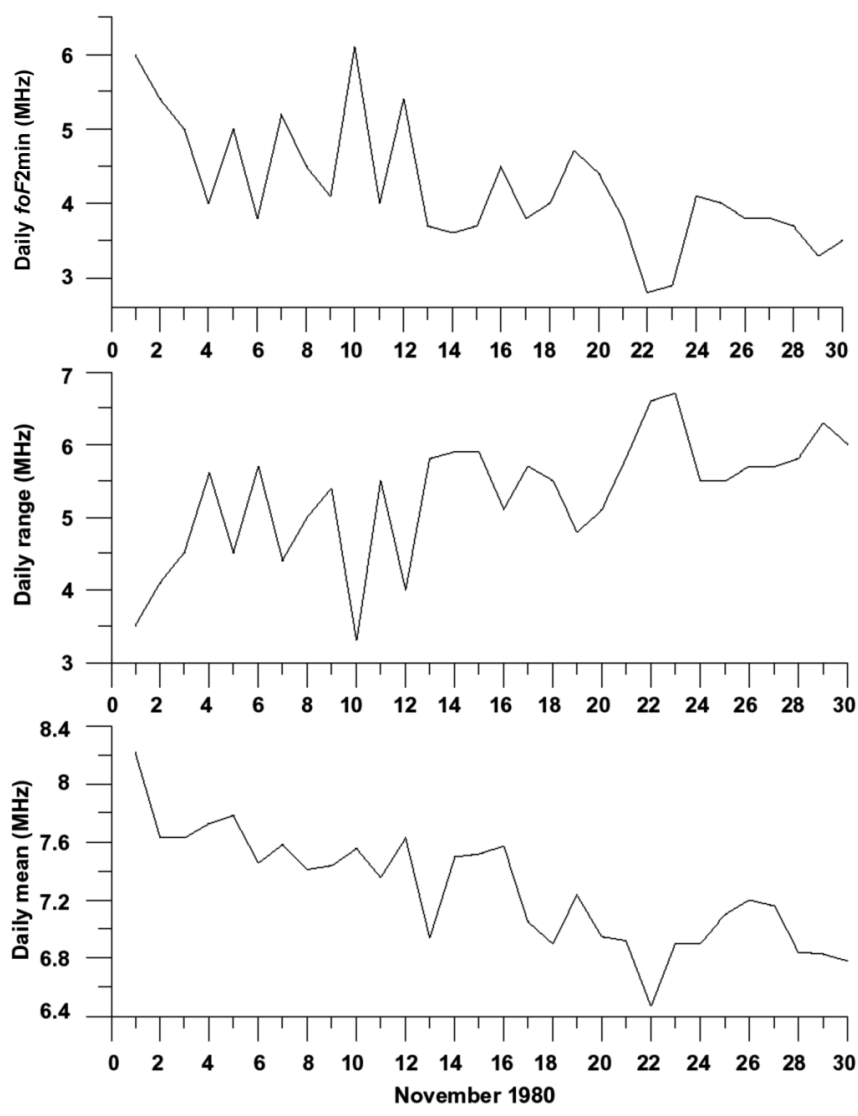

Fig. 11. From top to bottom: minimum daily values of the critical frequency, daily range of the critical frequency variation, daily mean value of the critical frequency for November 1980 (Athens ionospheric station). 

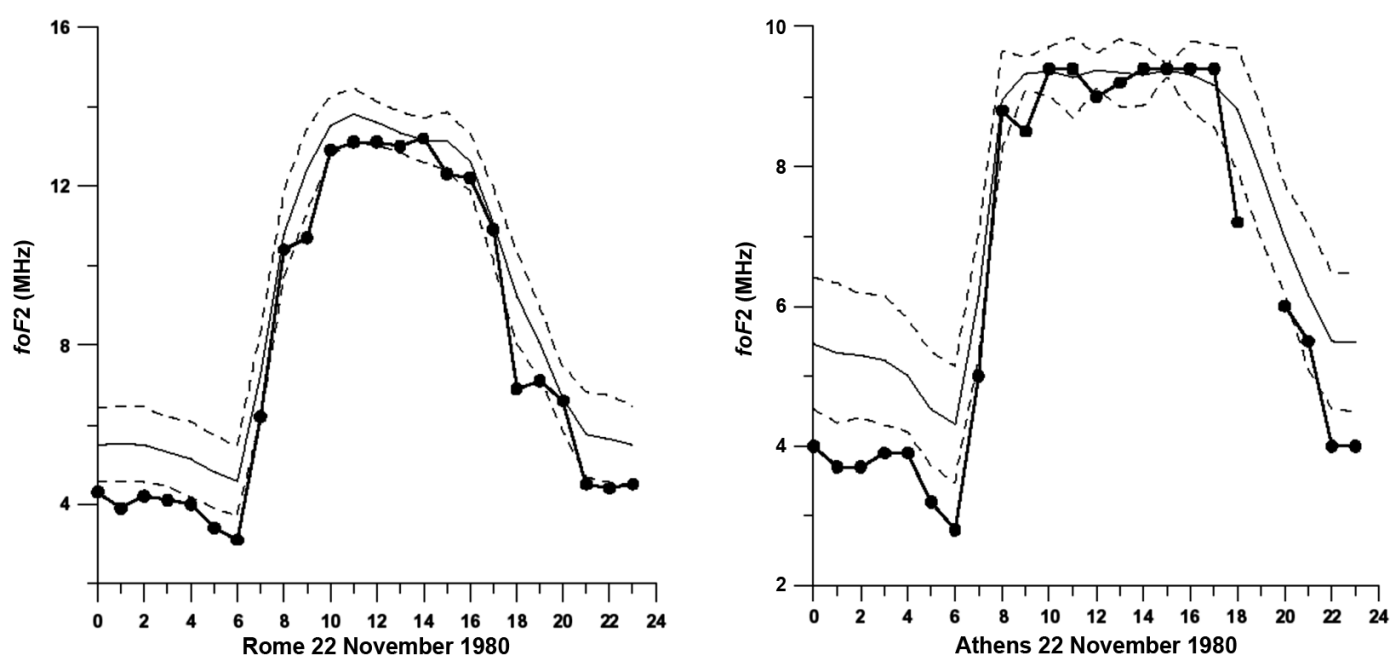

Fig. 12. Daily variations of the critical frequency (bold line with points) on $22 \mathrm{nd}$ November 1980 in Rome (left panel) and Athens (right panel). Continuous line - monthly mean, dashed lines $\pm \sigma$.

demonstrate this effect for other part of ionospheric data. Figure 10 shows the critical frequency variations from November 1980 for the Rome station for 06:00 and 18:00 LT. Both parameters demonstrate the absolute minimum for the month on 22 of November.

Pulinets et al. (2004) showed the increased ionosphere variability around the time of the seismic shock at the ionospheric stations close to the impending earthquake epicenter position. This is expressed in the form of the extreme values of the critical frequency, the range of the parameter variations, and in the magnitude of the mean daily values. All these parameters are shown in fig. 11 for the Athens ionospheric station.

From fig. 11 one can see that all three parameters presented for the whole month of November demonstrate the extreme values for the days 22 and 23. Such analysis is usually conducted when the variations are not very pronounced as in the considered case. One can expect the most unstable critical frequency behavior on 22 of November. At both stations the critical frequency does not exceed $2 \sigma$ (as expected, see fig. 12) but well above $\sigma$ for the nighttime and evening hours as one can see from the figure.

\section{Conclusions}

Concluding the Irpinia earthquake analysis we can state that the large number of variations of different parameters were observed around the time of the Irpinia earthquake, namely (see table I):

- Radon anomalies starting after the seismic swarm in May 1980 and continuing up to the time of the Irpinia earthquake registered at long distances from the epicenter.

- TIR anomalies starting 3 days before the earthquake and occupying large areas (more than $500 \mathrm{~km}$ ).

- Ionospheric anomalies registered by groundbased ionosondes at Rome and Athens 3 and 1 days before the seismic shock.

- Ionospheric anomalies registered by Intercosmos-19 satellite starting three days before the shock.

- Vertical topside electron density profile scale height anomalies manifesting the ion mass changes.

- VLF noises anomalies starting 3 days before the shock.

- Anomalies in the conjugated point manifesting the whole magnetospheric tube modifi- 
Irpinia earthquake 23 November 1980 - Lesson from Nature reviled by joint data analysis

Table I. Spatial and temporal parameters of anomalies registered around the time of Irpinia earthquake.

\begin{tabular}{|c|c|c|c|}
\hline Event, parameter & Date & Position & $\begin{array}{c}\text { Distance } \\
\text { from the epicenter }\end{array}$ \\
\hline Irpinia earthquake & 23/11/1980 & $40.61 \mathrm{~N}, 15.38 \mathrm{E}$ & 0 \\
\hline Radon anomaly, Rieti & $\begin{array}{l}\text { June-September, } \\
\text { November } 1980\end{array}$ & $42.42 \mathrm{~N}, 12.85 \mathrm{E}$ & $270 \mathrm{~km}$ \\
\hline Radon anomaly, Rome & June-November 1980 & $41.9 \mathrm{~N}, 12.48$ & $250 \mathrm{~km}$ \\
\hline $\begin{array}{l}\text { TIR anomaly close } \\
\text { to epicenter }\end{array}$ & $\begin{array}{l}3 \text { days before } \\
\text { the seismic shock }\end{array}$ & Apennines Peninsula & From 0 to $600 \mathrm{~km}$ \\
\hline $\begin{array}{c}\text { Ionospheric anomaly } \\
\text { (satellite) }\end{array}$ & $\begin{array}{l}2.5 \text { days before } \\
\text { the seismic shock }\end{array}$ & $30 \mathrm{~N}, 23 \mathrm{E}$ & $900 \mathrm{~km}$ \\
\hline $\begin{array}{c}\text { Ionospheric anomaly } \\
\text { (satellite) }\end{array}$ & $\begin{array}{l}1.8 \text { days before } \\
\text { the seismic shock }\end{array}$ & $\begin{array}{l}42.42 \mathrm{~N}, 12.85 \mathrm{E} \\
\text { Over Rieti radon anomaly }\end{array}$ & $270 \mathrm{~km}$ \\
\hline $\begin{array}{l}\text { Ionospheric anomaly } \\
\text { (Rome ionosondes) }\end{array}$ & $\begin{array}{c}3 \text { and } 1 \text { days } \\
\text { before earthquake }\end{array}$ & $41.9 \mathrm{~N}, 12.48$ & $250 \mathrm{~km}$ \\
\hline $\begin{array}{l}\text { Ionospheric anomaly } \\
\text { (Athens ionosondes) }\end{array}$ & 1 day before earthquake & $38 \mathrm{~N}, 13.73 \mathrm{E}$ & $785 \mathrm{~km}$ \\
\hline
\end{tabular}

cation through the electric field mapping along the tube.

From the presented analysis we can conclude that the temporal and spatial characteristics of the observed variations of geochemical, atmospheric and ionospheric parameters can be interpreted within the frame of the presented model of Lithosphere-Atmosphere-Ionosphere (LAI) coupling. This model does not make them a set of independent parameters but unites them in the cause-effect chain of physical processes preceding the earthquake. The characteristics of the registered ionospheric variations correspond to the main morphological features of ionospheric precursors of earthquakes described in Pulinets et al. (2003), the ionospheric variability corresponds to the statistical characteristics of the pre-earthquake ionospheric variations described in Pulinets et al. (2004) and Liu et al. (2004). So, accepting that the observed variations are associated with the earthquake preparation process one can try to estimate roughly the main parameters necessary for the short-term prediction: time, place, and magnitude of the impending earthquake. The time of the seismic shock may be estimated from the time of the first appearance of the ionospheric precursors. Statistically it was determined that for the strong earthquakes the ionospheric anomalies appear within the interval from 1 to 5 days before the seismic shock (Liu et al., 2004). In our case we were able to detect anomalies 2.5 days before the shock. So, using the statistical data, and the real experimental data, the time of the shock could be determined with the error 2.5 days. From the map of the ionospheric anomaly (taking into account the magnetic field lines inclination, the epicenter position can be estimated with a precision 200-300 km. Using the data of the thermal anomaly, one can try to put the epicenter position at the middle of the observed thermal anomaly, which will give even better estimation (near $100 \mathrm{~km}$ ). And, finally, the magnitude may be estimated using the size of the ionospheric anomaly and the Dobrovolsky formula (2). Scaling the size of the area from fig. $9 \sim 1800$ $\mathrm{km}$, radius $-900 \mathrm{~km}$ which corresponds to $M=[\log (900)] / 0.43=6.9$. It corresponds to the magnitude of the Irpinia earthquake. Of course, these estimations are very rough but at least they indicate the direction which may probably permit us to make the real short-term prediction in future. 


\section{REFERENCES}

Allegri, L., F. Bella, G. Della Monica, A. Ermini, S. ImPORA, V. SGRIGNA and P.F. BIAGI (1983): Radon and tilt anomalies detected before the Irpinia (South Italy) earthquake of November 23, 1980 at great distance from the epicenter, Geophys. Res. Lett., 10, 269-272.

Bardakov, V.M., B.O. Vugmeister, A.V. Petrov and A.A. CHRAMTSOv (2004): Excitation of VLF-Signals Under Earthquake Preparation Process (Irkutsk State Technical University, Irkutsk), p. 16 (preprint).

BElyAEV, A.A. (2001): Specific features of radon earthquake precursors, Geochem. Inter., 39 (12), 1245-1250,

BERnARD, P. and A. Zollo (1989): The Irpinia 1980 earthquake: detailed analysis of a complex normal faulting, J. Geophys. Res., 94, 1631-1647.

Biagi, P.F., A. ERmini and S.P. Kingsley (2001): Disturbances in LF radiosignals and the Umbria-Marche (Italy) seismic sequence in 1997-1998, Phys. Chem. Earth., 26, 755-759.

Bondur, V.G. and A.T. Zverev (2005): A method of earthquake forecast based on the lineament analysis of satellite images, Doklady Earth Sci., 402 (4), 561-567.

Boschi, E., D. Pantosti, D. Slejko, M. Stucchi and G. VALENSISE (Editors) (1993): Special issue on the meeting Irpinia dieci anni dopo Sorrento, November 19-24 1990, Ann. Geofis., XXXVI (1), pp. 376.

Bowman, D.D., G. Oulllon, C.G. Sammis, A. Sornette and D. SoRnette (1998): An observation test of the critical earthquake concept, J. Geophys. Res., 103, 24,359-24,372.

Boyarchuk, K.A., A.M. Lomonosov and S.A. Pulinets (1997): Electrode effect - Earthquakes precursor, BRAS Phys. Suppl. Phys. Vibrations, 61 (3), 175-179.

Boyarchuk, K.A., A.M. Lomonosov, S.A. Pulinets and V.V. HEGAI (1998): Variability of the Earth's Atmospheric Electric field and Ion-Aerosol Kinetics in the Troposphere, Studia Geophys. Geod., 42, 197-206.

BoyarchuK, K.A., A.V. Karelin and R.V. ShIRokov (2005): Neutral cluster and its influence on electromagnetic effects in the atmosphere, Izv. Atmos. Ocean. Phys., 41, 487-497.

Bricard, F., F. Billard and G. MAdelaine (1968): Formation and evolution of nuclei of condensation that appear in air initially free of aerosols, J. Geophys. Res., $\mathbf{5 4}, 39-52$.

Chmyrev, V.M., N.V. Isaev, O.N. Serebryakova, V.M. SoROKIN and Y.P. SobOLEV (1997): Small-scale plasma inhomogeneities and correlated ELF emissions in the ionosphere over an earthquake region, J. Atmos. SolarTerr. Phys., 59 (9), 967-974.

Chuo, Y.J., J.Y. Liu, S.A. Pulinets and Y.I. Chen (2002): The ionospheric perturbations prior to the Chi-Chi and Chia-Yi earthquakes, J. Geodyn., 33 (4-5), 509-517.

Depuev, V.H. and S.A. Pulinets (2004): A global empirical model of the ionospheric topside electron density, $A d v$. Space Res., 34, 2016-2020.

Deschamps, A. and G.C.P. KING (1980): The Campania Lucania (Southern Italy) earthquake of November 23, 1980, Earth Planet. Sci. Lett., 62, 296-304.

Dey, S. and R.P. SingH (2003): Surface latent heat flux as an earthquake precursor, Nat. Hazard Earth Syst. Sci. 3, 749-755.
Di Bello, G., C. Filizzola, T. Lacava, F. Marchese, N. Pergola, C. Pietrapertosa, S. Piscitelli, I. Scaffidi and V. Tramutoli (2004): Robust satellite techniques for volcanic and seismic hazards monitoring, Ann. Geophysics, 47 (1), 49-64.

Dobrovolsky, I.R., S.I. ZubKov and V.I. MYACHKIN (1979): Estimation of the size of earthquake preparation zones, Pure Appl. Geophys., 117, 1025-1044.

DunAJECKA, M.A. and S.A. Pulinets (2005): Atmospheric and thermal anomalies around the time of strong earthquakes in Mexico, Atmosfera, 18, 235-247.

Esposito, E., R. Pece, S. Porfido and G. Tranfaglia (2001): Hydrological anomalies connected to earthquakes in Southern Apennines (Italy), Nat. Hazards Earth Sys. Sci., 1, 137-144.

Filizzola, C., N. Pergola, C. Pietrapertosa and V. TraMUTOLI (2004): Robust satellite techniques for seismically active areas monitoring: a sensitivity analysis on September 7th 1999 Athens's earthquake, Phys. Chem. Earth, 29, 517-527.

Fraser-Smith, A.C., A. Bernardi, P.R. McGill, M.E. LADD, R.A. Helliwell and O.G. Villard JR. (1990): Low-frequency magnetic field measurements near the epicenter of the Ms 7.1 Loma Prieta earthquake, Geophys. Res. Lett., 17, 1465-1468.

HaYAKAWA, M. and O.A. MolCHANOV (Editors) (2002): Seismo-Electromagnetics: Lithosphere-Atmosphere-Ionosphere Coupling (Terra Scientific Publishing Co., Tokyo), pp. 477.

Hoppel, W.A. (1967): Theory of the electrode effect, J. Atmos. Terrest. Phys., 29, 709-721.

INAN, S. (2005): Researches for possible earthquake precursors in the Marmara region (NW Turkey), in Proceedings of the International Workshop «Early Warning Systems for Earthquake Monitoring by Using Space Technology», 1-2 February, 2005, Istanbul, Turkey.

italiano, F., M. Martelli, G. Martinelli and P. Mario NuCCIO (2000): Geochemical evidence of melt intrusion along lithospheric faults of the Suthern Apennines, Italy: geodynamic and seismogenic implications, $J$. Geophys. Res., 105, 13569-13578.

KhILYUK, L.F., G.V. ChILlinger, J.O. Robertson JR. and B. ENDRES (2000): Gas Migration. Events Preceding Earthquakes (Gulf Publiching Company, Houston, Texas), p. 390.

KIM, V.P. and V.V. HeGAI (1997): On possible changes in the midlatitude upper ionosphere before strong earthquakes, J. Earthquake Predict. Res., 6, 275-280.

Kim, V.P., V.V. KHEGAI and P.V. ILlich-SVITYCH (1994): On one possible ionospheric precursor of earthquakes, Phys. Solid Earth, 30, 223-226.

KIM, V.P., V.V. KHEGAI and L.I. Nikiforova (1996): On a possible distortion of the nighttime ionospheric $E$ region above a large-scale tectonic fault, Phys. Solid Earth, 31, 580-584.

KING, C.-Y. (1996): Gas geochemistry applied to earthquake prediction. An overview, J. Geophys. Res. 91, 12,269-12,281.

King, C.-Y., W. Zhang and B.-S. KIng (1993): Radon anomalies on three kinds of faults in California, Pure Appl. Geophys., 141, 111-124.

Kossobokov, V.G., V.I. KeILIS-BoroK, D.L. TurcotTe and B.D. Malamud (2000): Implications of a statistical 
physics approach for earthquake hazard assessment and forecasting, Pure Appl. Geophys., 157, 2323-2349.

Kouris, S.S., P. Spalla and B. Zolesi (2001): Could ionospheric variations be precursors of a seismic event? A short discussion, Ann. Geofis., 44 (2), 395-402.

Krewski, D., J. Lubin, J. Zielinski, M. Alavanja, V. CataLAN, R.W. Field, J. KLOTZ, E. LÉTOURNEAU, C. LYNCH, J. Lyon, D. Sandler, J. Schoenberg, D. Steck, J. Stolwijk, C. Weinberg and A.A. Wilcox (2002): Combined analysis of North American case control studies of residential radon and lung cancer: an update, Radiat. Res., 158 (6), 785-790.

Larkina, V.I., V.V. Migulin, O.A. Molchanov, I.P. KHAR' KOV, A.S. INCHIN and V.B. SCHVETCOVA (1989): Some statistical results on very low frequency radiowave emissions in the upper ionosphere over earthquake zones, Phys. Earth Planet. Inter., 57, 100-109.

Legen'KA, A.D., S.A. Pulinets and D. Gregori (1995): Reaction of the ionosphere to the Italian earthquake of November 23, 1980, Preprint IZMIRAN (Moscow), 12 (1081), p. 17.

Liu, J.Y., Y.I. Chen, S.A. Pulinets, Y.B. Tsai and Y.J. Chuo (2000): Seismo-ionospheric signatures prior to $M \geq 6.0$ Taiwan earthquakes, Geophys. Res. Lett., 27 (19), 31133117.

Liu, J.Y., Y.J. Chuo, S.A. Pulinets, H.F. Tsai and X. Zeng (2002): A study on the TEC perturbations prior to the Rei-Li, Chi-Chi and Chia-Yi earthquakes, in SeismoElectromagnetics: Lithosphere-Atmosphere-Ionosphere Coupling, edited by M. HaYAKawa and O.A. MolchANOV (Terra Scientific Publishing Co., Tokyo), 297-301.

Liu, J.Y., Y.J. Chuo, S.J. Shan, YB. Tsai, S.A. Pulinets and S.B. YU (2004): Pre-earthquake ionospheric anomalies monitored by GPS TEC, Ann. Geophysicae, 22, 15851593.

Martinelli, G., M. Mucciarelli and G. Valensise (1999): Relationship between the location of thermal springs and seismogenic faults in the Apennines, Italy, in Proceedings of the European Geophysical Society, XXIV General Assembly, 19-23 April 1999, The Hague, p. 99.

McCormick, R.J., C.J. Rodger and N.R. Thomson (2002): Reconsidering the effectiveness of quasi-static thunderstorm electric fields for whistler duct formation, $J$. Geophys. Res., 107 (A11), 1396

Molchanov, O.A. and M. HayaKawa (1998): Subionospheric VLF signal perturbations possibly related to earthquakes, J. Geophys. Res., 103, 17,489-17,504.

Molchanov, O.A., M. HayaKaWa, T. OndOH and E. KaWAI (1998): Precursory effects in the subionospheric VLF signals for the Kobe earthquake, Phys. Earth Planet. Interr., 105, 239-248.

MüHLEISEN, R. (1958): The influence of water on the atmospheric electrical field, in 'Recent Advances in Atmospheric Electricity', Proceedings of the 2nd Conference on Atmospheric Electricity, Mar 20-23, 1958, Portsmouth, New Hampshire (Pergamon Press), 213-221.

Ouzounov, D. and F. Freund (2004): Mid-infrared emission prior to strong earthquakes analyzed by remote sensing data, Adv. Space Res., 33, 268-273.

PARK, C.G. and M. DejnAKarintra (1973): Penetration of thundercloud electric fields into the ionosphere and magnetosphere, 1. Middle and subauroral latitudes, $J$. Geophys. Res., 78, 6623-6633.
PARROT, M. (2005): Seismo-electromagnetic effects observed by DEMETER in the ionosphere, in Proceedings of the International EMSEV2005 Workshop «Frontiers of Seismo-Volcano Electromagnetics», November 3-4, 2005, Puerto Vallata, Mexico.

Pulinets, S.A. (1989): Prospects of topside sounding, in WITS Handbook (SCOSTEP Publishing, Urbana, Illinois), no. 2, Ch. 3, 99-127.

Pulinets, S.A. (1998): Strong earthquakes prediction possibility with the help of topside sounding from satellites, Adv. Space Res., 21 (3), 455-458.

Pulinets, S.A. (2006): Space technologies for short-term earthquake warning, Adv. Space Res., 37, 643-652.

Pulinets, S.A. and K.A. BoyarchuK (2004): Ionospheric Precursors of Earthquakes (Springer, Berlin, New York), p. 316.

Pulinets, S.A. and A.D. Legen'KA (1997): First simultaneous observations of the topside density variations and VLF emissions before the Irpinia earthquake, November, 23, 1980 in magnetically conjugated regions, in Proceedings of International Workshop on SeismoElectromagnetics (University of Electro-Communications Publ., Chofu, Japan), 56-59.

Pulinets, S.A. and A.D. Legen'KA (2003): Spatial-temporal characteristics of large scale disturbances of electron density observed in the ionospheric $F$-region before strong earthquakes, Cosmic Res., 41 (3), 240-249.

Pulinets, S.A., A.D. Legen'KA and V.A. Alekseev (1994): Pre-earthquakes effects and their possible mechanisms, in Dusty and Dirty Plasmas, Noise and Chaos in Space and in the Laboratory, edited by H. KIKUCHI (Plenum Publishing, New York), 545-557.

Pulinets, S.A., V.A. AleKseEv, A.D. Legen'Ka and V.V. KHEGAI (1997): Radon and metallic aerosols emanation before strong earthquakes and their role in atmosphere and ionosphere modification, Adv. Space Res., 20 (11), 2173-2176.

Pulinets, S.A., V.V. Khegai, K.A. Boyarchuk and A.M. LOMONOSOV (1998a): Atmospheric Electric field as a source of ionospheric variability, Physics-Uspekhi, 41, $515-522$.

Pulinets, S.A., V.P. Kim, V.V. Hegai, V.K. DepueV and S.M. RADICELla (1998b): Unusual longitude modification of the nighttime midlatitude $F 2$ region ionosphere in July 1980 over the array of tectonic faults in the Andes area: observations and interpretation, Geophys. Res. Let., 25 (22), 4143-4136.

Pulinets, S.A., V.A. Alekseev, K.A. BoyarchuK, V.V. Hegai and V.KH. DEPUEV (1999): Radon and ionosphere monitoring as a means for strong earthquakes forecast, Nuovo Cimento C, 22 (3-4), 621-626.

Pulinets, S.A., K.A. BoyarchuK, V.V. Khegai, V.P. Kim and A.M. LOMONOSOV (2000): Quasi-electrostatic model of atmosphere-thermosphere-ionosphere coupling, $A d v$. Space Res., 26, 1209-1218.

Pulinets, S.A., K.A. Boyarchuk, V.V. Hegai and A.V. KARELIN (2002): Conception and model of seismo-ionosphere-magnetosphere coupling, in Seismo-Electromagnetics: Lithosphere-Atmosphere-Ionosphere Coupling, edited by M. HAYAKAWA and O.A. MOLCHANOV (Terra Scientific Publishing Co., Tokyo), 353-36.1

Pulinets, S.A., A.D. Legen'Ka, T.V. Gaivoronskaya and V.KH. DePUEV (2003): Main phenomenological fea- 
tures of ionospheric precursors of strong earthquakes, J. Atmos. Solar-Terr. Phys., 65, 1337-1347.

Pulinets, S.A., T.B. Gaivoronska, A. Leyva Contreras and L. CirAOLO (2004): Correlation analysis technique revealing ionospheric precursors of earthquakes, Nat. Hazards Earth Sys. Sci., 4, 697-702.

Pulinets, S.A., D. Ouzounov, A.V. Karelin, K.A. BoYARCHUK and L.A. POKHMELNYKH (2006): The physical nature of thermal anomalies observed before strong earthquakes, Phys. Chem. Earth, 31, 143-153.

Roble, R.G. and I. TzuR (1986): The global atmosphericelectrical circuit, in The Earth's Electrical Environment (Studies in Geophysics Series, National Academy Press, Washington D.C.), 206-231.

Rodger, C.J., N.R. Thomson and R.L. Dowden (1998): Testing the formulation of Park and Dejnakarintra to calculate thunderstorm dc electric fields, J. Geophys. Res., 103, 2171-2178.

RULENKO, O.P. (2000): Operative precursors of earthquakes in near ground atmosphere electricity, Vulcanol. Seismol., 4, 57-68.

RundLe, J.B., D.L. TuRCOTTE and W. KLEIN (Editors) (2000): GeoComplexity and the Physics of Earthquakes (Geophysical Monographs Series, American Geophysical Union, Washington D.C.), pp. 284.

RUZHIN, YU.YA. and V.A. LARKINA (1996): Magnetic conjugation and time coherency of seismoionsphere VLF bursts and energetic particles, in Proceedings of International Wroclaw Symposium on Electromagnetic Compatibility, Wroclaw, 645-648.

RuZhin, Yu.YA., V.A. LARKinA and A.KH. Depueva (1998): Earthquake precursors in magnetically conjugated ionosphere regions, Adv. Space Res., 21, 525-528.

Scholz, C.H. (1990): The Mechanics of Earthquakes and Faulting (Cambridge University Press, Cambridge).

Sengupta, D., A. Ghosh and M.A. Mamtani (2005): Radioactivity studies along fracture zones in areas around Galudih, East Singhbhum, Jharkhand, India, Appl. Radiat. Isotopes, 63, 409-414.

Silva, A.A. and L.H. Claro (2005): Surface air radon progeny at Saõ José dos Campos, Brazil, Atmos. Environ., 39, 4619-4625.

SMIRNOv, C.E. (2005): Characteristics of negative anomalies in the quasi-static electric field in the near-Earth atmosphere on Kamchatka, Geomagn. Aeron., 45, 265-269.
SmiRnov, V.V. (1992): Ionization in Troposphere (Gidrometeoizdat Publ. Sankt-Petersburg), p. 312.

Tiampo, K.F., J.B. Rundle, S. McGinnis and W. Klein (2002): Pattern dynamics and forecast methods in seismically active regions, Pure Appl. Geophys., 159, 24292467.

Timofeev, V.E., V.G. Grigor'ev, V.I. Morozova, N.G. SKRYABIN and S.N. SAMSONOV (2003): Effect of cosmic rays on the latent energy of atmosphere, Geomagn. Aeron., 43, 646-640.

ToutAin, J.-P. and J.-C. BAuBron (1998): Gas geochemistry and seismotectonics: a review, Tectonophysics, 304, 1-27.

Tramutoli, V., G. Di Bello, N. Pergola and S. PiscitelLI (2001): Robust satellite techniques for remote sensing of seismically active areas, Ann. Geofis., 44 (2), 295-312.

Tramutoli, V., V. Cuomo, C. Filizzola, N. Pergola and C. Pietrapertosa (2005): Assessing the potential of thermal infrared satellite surveys for monitoring seismically active areas. The case of Kocaeli (İzmit) earthquake, August 17th, 1999, Remote Sensing Environ., 96 (3-4), 409-426.

Tronin, A.A., M. HayaKawa and O.A. Molchanov (2004): Thermal IR satellite data application for earthquake research in Japan and China, J. Geodyn., 33, 519-534.

Tzur, I. and R.G. Roble (1985): The interaction of a dipolar thunderstorm with its global electrical environment, J. Geophys. Res., 90, 5989-5999.

VAlENSISE, G. (1993): Summary of contributions on the 23 November 1980, Irpinia earthquake, Ann. Geofis., XXXVI (1), 345-351.

WILDING, R.J. and R.G. HARRISON (2005): Aerosol modulation of small ion growth in coastal air, Atmos. Environ., 39, 5876-5883.

Zafrir, H., G. Steinitz, B. Ginzburg, B. Shirman and I. HrvolC (2005): Current achievements in the combined research of Rn emanation, Earth magnetic field and the seismo-activity variations, along the Dead Sea rift, Israel, as ground truth for space observations, in DEMETER Guest Investigators Workshop, 2-4 May, 2005, Paris, France.

ZMAZEK, B, M. ŽIVČIĆ, L. TODOROVSKI, S. DŽEROSKI, J. VAUPOTIČ and I. KoBAL (2005): Radon in soil gas: how to identify anomalies caused by earthquakes, Appl. Geochem., 20, 1106-1119. 